\title{
TEAM LEARNING: A POTENTIAL SOLUTION TO THE PROBLEMS OF LARGE CLASSES
}

\author{
Larry K. Michaelsen, The University of Oklahoma \\ Warren Watson, University of North Carolina at Charlotte \\ John P. Cragin, Chinese University of Hong Kong \\ and \\ L. Dee Fink, The University of Oklahoma
}

Colleges of business administration have faced several serious problems in the past few years: unprecedented enrollment increases coupled with limited financial resources; reduced availability of $\mathrm{PhD}$ students and graduates to serve as classroom teachers; and accreditation restrictions on the number of credit hours that can be taught by graduate faculty. In attempting to cope with these problems, many institutions have been forced to substantially increase class sizes to capitalize on the economies of scale. Unfortunately, this move to larger classes has often led to changes in both the instructional strategies that are employed and the content of the courses that are being taught. For example, the great majority of large classes are taught by the lecture method and student performance is evaluated through the use of true/false and multiple choice exams. This curtails both the opportunity and incentive for students to develop higher-level skills in communication and problem solving since feedback and rewards are based primarily on the ability to memorize and recall course concepts rather than on how well these concepts can be utilized in solving problems.
The instructional strategy and course content changes that generally accompany a shift to larger classes also eliminate many of the motivating characteristics of the tasks of both the student and instructor. For example, students receive less feedback about their work (usually limited to the results of mid-term and final exams), produce less significant "products" (e.g., multiple choice exams versus application oriented exams and projects), and experience little variety in their work (a steady diet of reading, listening, taking notes, memorizing, and taking exams). All too often these conditions produce apathy, poor academic performance, increased demands for individual help, high absenteeism, and even overt hostility toward the class and the instructor (e.g., Filley et al., 1979).

Large classes often have a negative impact on instructors as well. The reduced interaction with students frequently means that we receive less feedback on our classroom performance, perform less significant tasks (largely limited to dispensing facts), and experience less variety (i.e., preparing and presenting lectures) and greater quantity (e.g., more students to 
tutor and/or counsel). In addition, many of us feel uncomfortable extolling the virtues of high-quality work while condoning a system that often has the opposite effect for both students and faculty.

The purpose of this paper is to describe an instructional format that has proven to be effective in offsetting many of the problems that are usually encountered in teaching large classes. This approach, Team Learning, was originally developed for use in Organizational Behavior classes of up to 45 students, and subsequently has been modified successfully for classes of up to 175 students and for a wide range of physical and social science courses.

\section{Team Learning}

The heart of the Team Learning approach is extensive classroom use of permanent, heterogeneous, six or seven member student work teams to accomplish learning objectives. Some of the prominent features of the Team Learning process that will be discussed below include: (1) the development of basic conceptual skills through an instructional activity sequence of (a) exposure to course concepts through individual study, (b) individual and group preinstructional exams with immediate feedback, ${ }^{1}$ and (c) pinpointed minilectures to alleviate deviciences identified by the exams; (2) extensive use of problems, simulations, and experiential exercises to provide students with opportunity to develop the ability to apply course concepts; and (3) grading based on a combination of individual performance, group performance, and peer evaluation. ${ }^{2}$

\section{Team Learning vs. Other Group-Oriented Instructional Formats}

The Team Learning process differs from the typical use of groups in a variety of ways. Among the most important are the composition of the groups, their centrality in the instructional process, the sequence of instructional activities, and the strategies employed to minimize the impact of problems that may occur in the functioning of the project teams.

Nature of Team Learning Groups - Probably the most common use of groups is as a temporary supplement to enrich students' experience in predominately instructor-centered classes. For example, groups are often used to identify issues to be discussed in a total class setting or are assigned to complete a specific project such as preparing a presentation for the class or making a series of decisions connected with a computer simulation. The use of groups to supplement instructor-centered activities has proven beneficial ${ }^{3}$ but their contribution is largely restricted to providing a richer climate for the development of cognitive understanding.

Team learning groups by contrast are permanent and purposefully heterogeneous, ${ }^{4}$ and their work is the central focus of class activity. Consequently, the teams can harness group forces in ways not possible for groups used on a limited basis. For example, the potential contribution of the groups in the cognitive domain is greatly magnified because heterogeneous groups have high creative potential (Goldman, 1965) when they have the opportunity to develop into effective problem-solving entities (Thibaut \& Kelley, 1969). Similarly, the groups can become cohesive enough to have a major impact on both the attitudes and the behavior of their members (Shaw, 1980), as is evidenced by high attendance and low dropout rates. Finally, group interaction is intense enough to provide credible examples of the pressures that students will face in their future jobs.

Sequence of Instructional Activities - Most group oriented instructional approaches follow the traditional instructional activity sequence of instructor input and individual study followed by application oriented activities (e.g., cases, projects, simulations) and then an exam. As a result, instructors encounter at least two problems. One is that students who put off studying until just before an exam are a liability during application oriented activities. The other is that since instructor input is the first activity in the sequence, the exams are of little or no help in providing insights into what concepts need to be covered in class (Bloom, Hastings, \& Madaus, 1971).

The primary instructional activity sequence in Team Learning is: individual study - individual exam - group discussion and exam - instructor input application-oriented activities. ${ }^{5}$ This sequence has the advantage of:

(1) placing responsibility for learning basic conceptual material first on individual students (individual study) and second on the group and the instructor,

(2) providing students immediate feedback on how well they are doing (discussion during group exam and scoring of individual exams),

(3) providing a forum for peer teaching (discussion during group exam and during later application-oriented activities, projects, and exams),

(4) providing the instructor with specific information on concepts about which additional input is needed (reducing the amount of time used for instructor input by 
largely eliminating coverage of material that students already understand - a benefit for students and instructors alike),

(5) providing groups with information about their member's level of preparation (facilitating the development of performance-oriented groups norms),

(6) showing students (and instructor) that groups can teach their members (group scores average over 90 percent and are above their highest individual member in more than 95 percent of the groups), and

(7) insuring that students develop a working familiarity with course concepts before application-oriented activities, projects, and exams.

Strategies for Building and Maintaining Group Cohesiveness - The most common strategies for building and maintaining the cohesiveness of classroom groups are direct interventions by the instructor and/or training students to manage the group and solve problems that arise (e.g., Bouton, 1980). In large classes the feasibility of either of these strategies is doubtful. Consequently, instructors of large classes are usually forced to rely on someone else for the maintenance of classroom groups. Thus, the responsibility for solving intragroup problems often falls on paid assistants, students who are being given course credit (Bradford \& LeDuc, 1975), or class members who have been promoted into "management" positions by the instructor (Cohen, 1976).

The Team Learning process, however, makes it possible for group members to resolve their own maintenance problems by establishing external conditions that make it unlikely that significant intragroup conflicts will occur. For example, deliberately forming heterogeneous groups minimizes the probability that previously established relationships will stimulate the development of subgroups. Another key activity that promotes the development of cohesive groups is allowing students to determine the degree to which group performance will contribute to their grade. This helps build cohesiveness in several ways. First, self-imposed evaluation criteria are much more likely to be accepted and internalized. Second, given the opportunity to choose, students consistently establish criteria that place a premium on cooperative effort. ${ }^{6}$ Third, a high level of group cohesiveness is fostered by the process used to set grade weights (Michaelsen et al., 1981). As the semester progresses the Team Learning process utilizes heavy task demands and performance oriented intergroup competition to further build and maintain group cohesiveness.
Results of Using Team Learning in Large Organizational Behavior Classes - Results from using the Team Learning process in large undergraduate classes (120-plus students) suggest that it is possible to achieve a high level of student understanding of basic conceptual material and a variety of other important educational objectives as well. These include the enhancement of students' application, analysis and synthesis skills (Bloom, 1972), development of positive attitudes toward the class and the field of study, and the near elimination of problems with respect to withdrawals and absenteeism.

Development of Basic Conceptual Skills Evidence of the effectiveness of Team Learning in developing students' understanding of basic conceptual material comes from several sources. First, individual scores on identical true/false, multiple choice, minitests have been virtually the same in large undergraduate classes (120-plus students) as in graduate classes of 20 to 35 students. Second, students' evaluations of their own progress on "learning fundamental principles, generalizations and theories" has consistently been at approximately the 90th percentile of the course that has been evaluated through the use of the IDEA evaluation instrument developed at the Center for Faculty Education and Development at Kansas State University. ${ }^{7}$ Finally, individual and group scores on a "comprehensive minitest" given as a review for the final exam have been quite impressive ( 82 percent for individual and 92 percent for groups). ${ }^{8}$

Development of Application, Analysis and Synthesis Skills - A key feature of the Team Learning process is that groups rather than individuals produce much of the material that is used for evaluation purposes. This makes it possible, even in large classes, to assign and evaluate several major application-oriented projects and/or exams while maintaining the instructor's grading load at a manageable level. Consequently, with Team Learning, students receive timely feedback on application oriented projects and exams first from their peers and second from the instructor. This feedback, in turn, provides the opportunity to develop application, analysis, and synthesis skills. As a result, performance exams treating complex case material (e.g., novels and full-length feature films) has been of consistently high quality. In addition, student progress on "improvement of thinking and problem solving skills" in large Team Learning classes has been consistently rated well above the 90th percentile of the IDEA norms.

Student Attitudes - Student attitudes toward the course have been very positive. Although the amount 
of reading and other work in the course has been rated above the 90th percentile compared to other courses using the IDEA instrument, students also rate it as one of the top two courses in the college of business. Furthermore, when asked to indicate how the size of the class affected what they gained from taking the course, an average of 50 percent of the students maintain that the large size was actually an advantage to learning ("helped more than it hurt") while 42 percent selected one of two neutral categories ("didn't have much effect," or "helped and hurt about equally"'). Only eight percent indicated that the large class size "hurt more than it helped." In addition, student ratings of the extent to which the course resulted in "more positive feelings toward this field of study" have been above the 90th percentile of the IDEA norms.

Attendance - Even in large classes, the Team Learning process requires students to become personally involved with their peers. As a result, over 99 percent of the students who have signed up for the class have also maintained their enrollment throughout the semester and an average of over 97 percent have been present each time the class has met. ${ }^{9}$ Furthermore, approximately 65 percent of the students identify either "feelings of responsibility for" or "expectations of" the group as being the most important factor in whether or not they attend class. Other factors included "interesting class" (five percent), "instructor expectations" (two percent), and "grades" (28 percent).

\section{Additional Positive Results from Team Learning} - The Team Learning instructional process have produced a number of other desirable outcomes in a wide variety of physical and social science courses. ${ }^{10}$ Many of these outcomes result from the intensive interaction required in the project teams and the incentive system designed to encourage members to support and provide inputs into the group. Consequently, students better prepared in subject matter are rewarded through the peer evaluation because they help other team members acquire basic skills and at the same time develop their own teaching skills. Older students returning to school are rewarded because they provide a real-world perspective in problem-solving activities and gain confidence in their ability to work and compete with younger students. Students who have academic preparation or are from other cultures are rewarded for raising relevant questions while expanding the horizons of problem-solving discussions. In addition, the Team Learning process gives students experience with working in groups, a bonus to the students in later course work and in employment settings where group problem solving and project team skills are important to job success.

\section{Adoption Considerations}

Although the Team Learning process has been successfully employed by a variety of instructors and in a wide range of disciplines, several of its unique features can result in problems particularly for the first time users. These include (1) forming groups, (2) uncertainties inherent in the instructor's role, (3) start-up costs, (4) the grading system, and (5) resistance to nontraditional methods in a traditional environment.

Forming Groups - For example the groups are most effective when they groups contain members with a wide variety of viewpoints and at least one individual with the specific skills required for the completion of their assigned tasks. " In addition, the existence of previous friendship between part of the members of newly formed groups can impede the development of group cohesiveness. Consequently, Team Learning groups should be instructor selected rather than selfselected since their effectiveness is dependent on the characteristics and resources of their members.

The group formation process consists of (1) obtaining an inventory of students' backgrounds and competencies, (2) identifying an appropriate skill mix and (3) assigning students to groups. One frequently used method for accomplishing these tasks is simply asking students to respond either vocally or by raising their hands to a series of questions about their backgrounds, then starting with the least common critical category, having students stand up to be "counted off" into groups. Alternatively, some instructors prefer to collect the background information using a questionnaire and then sort the students into groups between the first and second meeting of the class.

Uncertainties in Instructor Role - Some instructors have difficulty adjusting to the instructional activity sequence of individual study, individual exam, group exam, and instructor input. When this sequence is followed, instructors must be prepared to respond to a broad range of questions resulting from the testing process. In addition, giving immediate feedback as part of the testing process can create student-instructor conflict. As a result, the more successful instructor is comfortable with the subject matter and can channel students' emotional involvement into constructive work.

Another concern of some instructors in the Team Learning process is the reduced amount of instructorcentered activity. Many instructors using the Team Learning process for the first time are uneasy about 
"wasting time" on group exams. This is often alleviated when the instructor analyzes the results. Unfortunately, however, some instructors have been unwilling to compute the scores and make appropriate comparisons until after they have begun to question the value of the process.

Start-Up Costs - Most instructors are faced with start-up costs in three areas when they use the Team Learning Process for the first time. These areas are: (1) reorganizing the material to be taught; (2) developing group oriented classroom activities; and (3) establishing an appropriate grading system.

Organization of the Material - The Team Learning instructional activity sequence in which testing precedes instructor input may require instructor to make as many as three modifications in the organization of the material they are teaching. First, the topics must be sequenced so that each provides a conceptual foundation for the next. Second, tests must be devised that allow the instructor to detect and correct misunderstandings before moving on to the next topic in the sequence. Third, the material should be divided into relatively small units so that misunderstandings can be corrected before students experience difficulty in comprehending new material or until the errors have been compounded in further misinterpretations of additional material (Bloom, 1971). The most time consuming of these changes is usually the time and effort required in preparing exam questions. This occurs for a variety of reasons, including the facts that the exams are: (1) more frequent; (2) given at the beginning rather than the end of major units of instruction; and (3) the primary means the instructor has to assure that students have developed an understanding of course concepts before moving on to application oriented activities or to the next topic in the instructional sequence. The time and effort required for sequencing of the topics can often be accomplished by the selection of a well designed text; the division of the material into smaller units is often more of a problem for secretaries than for instructors.

Developing Group Oriented Activities - One of the unique features of Team Learning that results in start-up costs is that less class time is used for acquainting students with terminology and concepts. ${ }^{12}$ As a result, instructors who usually lecture are faced with the task of developing activities that are appropriate for group work and that focus on concept application.

Ideally each activity that is used in the Team Learning process should allow the instructor to simultaneously accomplish three objectives: (1) provide feed- back on students' understanding of course concepts; (2) provide the opportunity for peer teaching; and (3) build group cohesiveness. Some of the most common types of activities that have been successfully adapted for Team Learning groups are tests, problems, case analyses, and role plays.

The type of activity, however, is far less important to its successful use in the Team Learning process than two other characteristics. To be effective any group task must be (1) carefully structured so that students clearly understand what kind of a "product" the group is to produce and (2) sufficiently challenging that input from a majority of group members is required. ${ }^{13}$ Thus, for example, when tests are given to groups, the usual form of the answers should be clearly specified in advance and questions should be difficult enough that they would frequently be missed by members working individually but answered correctly following a group discussion.

The Grading System - In most university settings, a major factor in how well the Team Learning process will work is students' perceptions of the relationship between the effort they will be required to expend and the grades they will receive in their courses. Consequently, the grading system must provide incentives for each of the kinds of student behavior that is required for effective group problem solving. These include incentives for (1) individual preparation, (2) group performance, and (3) maintaining the group by being responsive to group needs (e.g., obtaining resources, volunteering for extra work, etc.).

Incentives for individual preparation are needed for two reasons. One is that group interaction is not an efficient means for the acquisition of new information $^{14}$ (Bruffe, 1978). The other is that when only one or two members are prepared for projects, activities or exams, group productivity is likely to be low and the potential for conflict between group members high.

Incentives for group performance and for maintaining the group are needed for the development of a setting in which peer teaching can occur. A grading system in which group performance "counts" both legitimizes and stimulates the expenditure of effort on group tasks. Similarly, having grades partially determined by students' responsiveness to needs of their peers minimizes the possibility that students will attempt to slide by on the efforts of their group.

Ironically, however, employing a grading system in which group performance and contribution to the groups (usually based on peer evaluations) can also be a problem. This is because students are often apprehensive about having part of their grade based on criteria over which they perceive that they have little or no control. To solve this problem most instructors 
who have used the Team Learning process have also employed an exercise described by Michaelsen et al. (1981) in which the instructor specifies that portions of the grade must be based on individual performance, group performance, and individual contribution to the group and by involving students in the weighting of each dimension.

To date, Team Learning users have encountered only two grading-system problems in connection with the "Grade Weight Setting Exercise" (Michaelsen et al., 1981). The more common of these stems from the fact that group scores are so much higher than individual scores on exams and projects. As a result, instructors using the Team Learning process for the first time have sometimes found themselves being forced to allow a marginal student to earn a " $C$ " or even a " $B$ " simply because the student belongs to an effective group. ${ }^{15}$ The other problem was encountered by an engineering instructor using the Team Learning process in one of two 175-student classes. He inadvertently failed to include either an incentive for individual day-to-day preparation or a mechanism through which groups could monitor the level of preparation of their members. As a result, many students did not complete the assigned homework. This appeared to increase the friction in some of the project teams but had a mixed impact on the performance on individual exams. A comparison of test scores from these classes and from a traditional class covering the same material revealed that Team Learning students who voluntarily completed the homework gained even further from the interaction in the project teams but that those not prepared each day fell behind. Apparently the increased personal attention in the Team Learning class was not enough to make up for lack of individual preparation.

Resistance to a Nontraditional Approach Instructors who adopt the Team Learning process can expect some initial resistance from students and some long-term resistance from fellow faculty members. Most student resistance is related to a concern about having a part of the grade determined by group performance and peer evaluations. This concern, however, is largely alleviated by having students determine the "weights" for the performance criteria employed in the grading system (Michaelsen et al., 1981). Beyond that, a few students (usually well below five percent) continue to have negative feelings about the Team Learning process because they want more input and direction from the instructor and/or they feel that they are "guinea pigs" in an experiment.

Fellow faculty members' resistance to the Team Learning process also stems largely from a concern about grades. The problem arises because, student attitudes and performance being substantially improved, Team Learning instructors tend to give few low grades and higher grades overall. In a traditional setting, this can be interpreted as sacrificing academic "rigor" in favor of increased popularity. A variety of strategies can help to reduce the severity of the problem. These include grading on a modified curve (Michaelsen et al., 1981), documenting the effects of the process, and involving fellow faculty members in the evaluation process. Unfortunately, however, in many settings innovative instructors are continuously on trial, and the "jury" can be particularly hostile when the innovation involves the use of groups, when fewer low grades are given, and when students appear to enjoy the process.

\section{An "Ounce of Prevention" - The Key to the Effective Use of Team Learning in Large Classes}

The effectiveness of the Team Learning process in large classes stems from the fact that instructors have fewer relationships to manage since they interact primarily with groups rather than individuals. Consequently, most of the potential problems associated with the use of Team Learning in large classes can be avoided by establishing conditions and procedures that support the development of instructor-to-group relationships. Some areas in which preplanning is particularly helpful in this regard are: (1) the physical layout of the classroom; (2) managing the materials; (3) providing immediate instructor feedback; (4) handling student challenges; and (5) the coordination of classroom activities.

Physical Layout of the Classroom - The ability to manage groups is dependent on locating and/or modifying a classroom in which project teams can (1) work as a group with a reasonable degree of comfort and (2) be readily identified by the instructor and other groups. The ideal classroom is one in which projectteam members can sit at a table or in appropriately arranged individual chairs. Less desirable, but workable nevertheless, is a tiered amphitheater-style classroom in which project-team members in adjacent rows can interact by temporarily standing or turning their chairs around. Once the groups have been assigned to a work area, an inexpensive yet effective means of identification is through the use of numbered styrofoam cups mounted on top of "flagpoles" (made from a dowel inserted in a hole in a wooden block) placed on the tables around which the teams work or suspended from the ceiling (in rooms with individual table arm chairs).

Another potential problem with the physical layout 
of the classroom is simply the time it takes to perform the necessary physical labor. Often the only solution seems to be to make each group responsible for preparing its assigned area and for restoring it to its original condition at the end of class.

Management of Materials - One characteristic of Team Learning is the volume of material required for minitests, experiential exercises, and other interactivetype activities. Consequently, the time required to hand out materials and/or collect assignments can be prohibitive in large classes. Advanced planning, however, can substantially reduce the seriousness of the problem. For example, preparing for each group one or more numbered manila folders containing the materials needed on any given day can nearly eliminate the class time required for handing out materials. The folders can be placed in a portable "filing bucket" ${ }^{16}$ at the front of the room, and the groups can be trained to pick up their folders at the beginning of class and to turn them in at the end. In addition, we establish a rule that a paper clip on a folder means that the material inside should not be passed out until we are ready to use it in the class. This allows us to coordinate the distribution of materials to support the learning process.

The folders also provide an effective means of collecting materials. For example, we establish the rule that the only way to turn in individual assignments (e.g., answer sheets on minitests) is in a designated folder. Thus, all materials are received in a standardsized, clearly labeled form, and the total number of items to keep track of coincides with the number of groups rather than with the number of individuals in the class. In addition, the folders provide an effective means of controlling materials. For example, if a check of the folders indicates that we handed out six exams to a particular project team and had only five turned in, we simply inform the group of the shortage and ask that they find the missing test. (They always do.)

Providing Feedback - The Team Learning process depends on students receiving two kinds of feedback. One is feedback on understanding of course concepts. This is provided by group discussions and during instructor's evaluations of individual and group projects and exams. The other is feedback to the groups about project teams members' attendance and individual preparation. Information on these variables are essential to the development, maintenance, and enforcement of performance oriented peer group norms. We provide feedback on individual preparation and attendance to the groups through the use of a form which is permanently attached to the manila folder used in distributing and collecting materials. On this form, group members record their own scores on individual and group assignments (students generally are honest) and absences, including whether or not the absence was known in advance. ${ }^{17}$

Handling Student Challenges - In classes that are taught using the Team Learning process, students are willing to disagree with the instructor because they develop a social support base in their groups. This willingness to disagree provides valuable feedback on course process and content. In large classes, however, challenges can become a major problem, because each challenge disrupts the flow of activity for the entire class.

In particular, students' willingness to disagree can be a problem in providing feedback on group exams. Although the groups are accurate in their work, the emotional commitment to occasional incorrect answers is often very high. Discussing issues that surface during examination feedback and allowing the groups to "let off steam" until they are willing to consider alternatives can be time consuming (and nerve wracking). In a large class the sheer number of issues can be overwhelming even though the issues themselves might not be complex.

Two methods are effective in handling disagreements while giving feedback on the group tests. For multiple-choice/true-false minitests we use a modification of the "appeals" proced ure described by Bludoin (1980). ${ }^{18}$ Allowing groups to write appeals on questions they miss helps in several ways. First, in the process of reviewing their assigned readings as their appeal, students often discover they (not the instructor) were wrong. Second, writing the appeal reduces the need to let off steam. Third, both the students and the instructor are more likely to respond rationally (rather than emotionally) since the actual decision as to whether or not the appeal is granted is generally delayed until a later time. Finally, the appeals can be used to improve the questions themselves.

Essay exams created more difficult situations than objective exams because essay issues are more complex. With essay exams we provide feedback by forming temporary groups to discuss what we have identified as an "ideal" answer. ${ }^{19}$ Discussions within these newly formed groups quickly resolve misunderstandings since the majority of the members usually understand and agree with the "ideal" answer. As a result, win-lose confrontations seldom occur and subsequent class discussions focus on additional perspectives that should be considered rather than why we were wrong.

Coordinating Classroom Activities - Finding ways to coordinate group activities can be challenging 
in large classes. Group discussions, for example, produce high levels of noise, and group activities can generate a momentum difficult to overcome. Similarly, keeping the groups working at approximately the same pace is difficult but failing to do so can be disastrous.

Coping with Noise. There is no complete solution to the problem of the noise generated by group work, but instructors using the Team Learning process can reduce its severity. One method is to use a whistle to get students' attention. Another is to enlist the help of the students themselves. This can be done by simply waiting for their help once a majority are aware that you are trying to get the attention of the class. Finally, visual cues (e.g., cards indicating the time left for a group activity) are a great help.

Coping with Momentum. The most effective method we have found for coping with group momentum is to reduce the amount of communication required for coordinating group activities. We maintain pooled interdependence (Thompson, 1967, p. 54) between groups and coordinate group activities by standardizing their output (Thompson, 1967, p. 56). For example, for the "New Truck Dilemma" role play (Maier, Salem, \& Maier, 1976), instead of having the groups report their results sequentially, we structure the information-collection process as follows:

(1) We hand out the role-play instructions, a felt-tip marker, and $36 \times 10$ inch posterboard on which is a group number, the drivers initials and three empty boxes. Actually this board is an oversized version of the report-back chart recommended by Maier and others (1976, p. 46).

(2) After the role play, we explain how to fill out the chart and, using an overhead projector, show two or three examples.

(3) We ask that each group complete its own chart, turn it in, and take a five minute break.

(4) We tape the results on the wall, grouping them according to who got the new truck.

(5) After the break we give students a few minutes to examine the charts and then discuss the results. ${ }^{20}$

As a result of this procedure we are able to collect and utilize the information from all the groups without forcing each of the groups to wait their turn to report results.
Timing. One effective method for dealing with the potential problems created by the fact that groups work at different paces is schedule group work for the end of the class and allow students to leave when they complete their work. For other activities including minitests, we use what we call a " $5-5$ " rule; when five groups ( 25 percent of the class) are through, the remaining groups have five minutes left before they must turn in their answer sheets. This procedure has several positive features including the facts that it (1) automatically adjusts for the time requirements of specific activities, (2) stimulates intergroup competition, and (3) can be managed using visual cues.

\section{Conclusion}

The Team Learning process effectively accomplishes a variety of learning objectives in a large class setting. The cost advantages are obvious. Not so obvious is the fact that the impact of the Team Learning process is even greater in large classes than in small. For example, experiential exercises always produce data sufficient to provide firsthand evidence of the points to be covered. Second, the volume of data generated by the class makes the experience a more valuable teaching tool (e.g., students react in a very different way when five or six or all six groups outperform their best individual member than when the same thing occurs in 19 of 20 groups). Third, many students see for the first time the impact of structure on their own and other class members' behavior. (In smaller classes, students are more likely to attribute outcomes to the influence of the instructor.)

The use of Team Learning also enriches the experience for the instructor as well. In part this occurs because students learn most of the basic concepts either on their own or from their peers which both reduces the absolute number of requests for individual help and makes those that do occur more challenging and rewarding. In addition, the Team Learning process increases the amount and candidness of student feedback to the point that, even in large classes, teaching is still a very personal experience. Finally, learning about management is far different from having to use management principals. Once you have put yourself in a position in which success or failure is totally dependent on your ability to apply what you think you know, your feelings about the material will never be the same. 


\section{References}

Bloom, B. S., Taxonomy of Educational Objectives: The Classification of Educational Goals. New York: David McKay Co., Inc., 1956.

Bloom, B. S., Hastings, J. T., and Madaus, B. F., Handbook on Formative and Summative Evaluation of Student Learning. New York: McGraw-Hill Book Company, 1971.

Bouton, C., The Cooperative Learning Project Student Manual. Washington, D.C.: University of the District of Columbia, 1981.

Bradford, D., and LeDuc, R., "One Approach to the Care and Teaching of Introductory Organizational Behavior." The Teaching of Organization Behavior, 1(1), 1975, 23-30.

Bruffe, K. A., A Short Course in Writing: Practical Rhetoric for Composition Courses, Writing Workshops and Tutor Training Programs (2nd. edition). New York: Winthrop, 1980.

Cohen, A. R., "Behond Simulation: Treating the Classroom as an Organization." The Teaching of Organization Behavior, 2(1), 1976, 13-18.

Filly, A. C., Foster, L. W., and Herbert, T. T., "Teaching Organizational Behavior: Current Patterns and Duplications." Exchange: The Organizational Behavior Teaching Journal, 4(2), 1979, 13-18.

Finkel, D. L., and Monk, G. S., "The Design of Intellectual Experience." The Journal of Experiential Education, 3, 1979, 31-38.

Goldman, M., "A Comparison of Individual and Group Performance for Varying Combinations of Individual Ability." Journal of Personality and Social Psychology, 1, 1965, 210-216.

Goldschmid, B., and Goldschmid, M. L., "Peer Teaching in Higher Education: A Review." Higher Education, 5, 1976, 9-33.

Laughlin, P., and Johnson, H., "Group and Individual Performance on a Complementary Task as a Function of Initial Ability Level." Journal of Experimental Social Psychology, 2, 1966, 407-414.

Maier, N. R. F., Solem, A. R., and Maier, A. A., The Role Play Technique: A Manual for Supervisory Training. LaJolla, California: University Associates Press, 1975.

Michaelsen, L. K., Cragin, J. P., and Watson, W. E., "Grading and Anxiety: A Strategy for Coping." Exchange: The Organizational Behavior Teaching Journal, 6(1), 1981, 8-14.

Michaelsen, L. K., Watson, W. E., and Fink, L. D. "Preinstructional Mini Tests: A Practical Approach to Mastery Learning." Unpublished manuscript, The University of Oklahoma, April 1982.

Shaw, M. E., Group Dynamics: The Psychology of Small Group Behavior (3rd edition). New York: McGraw-Hill, 1981.

Thibaut, J. W., and Kelley, H. H., The Social Psychology of Small Groups. New York: Wiley, 1959.

Thompson, J. D., Organizations in Action. New York: McGraw-Hill, 1967.

\section{Footnotes}

'For an explanation of the rationale for and mechanics of the examination process, see "The Mini-Test: An Exercise for Evaluation, Teaching, and Building Groups"' (Michaelsen \& Watson, 1981).
${ }^{2}$ The relative "weight" for these three performance areas varies from semester to semester and is set by the students through the use of the "Grade Weight Setting Exercise" described in Michaelsen, Cragin, and Watson (1981).

${ }^{3}$ The "Learning Cell" (Goldschmidt, 1971), the Peer Tutoring Writing Workshop (Bruffe, 1980), and the classroom workshop approach (Finkel and Monk, 1979) are excellent examples of the way in which temporary and project-specific groups can be used to increase the effectiveness of instruct or-centered classroom activities.

'The specific dimensions vary from course to course, but an attempt is always made to form groups that are heterogeneous with respect to characteristics likely to affect member's approach to or input in the project teams (e.g., previous coursework, employment history, cultural background).

${ }^{5}$ See Michaelsen, Watson, and Fink (1982) for a more detailed description of the logic for and results of the individual and group examination format used in Team Learning.

${ }^{6}$ The average weight for group performance has ranged from 20 percent in an engineering course to 65 percent in an organizational behavior course. The approximate average is 40 percent.

${ }^{7}$ Percentile scores on the IDEA course evaluation instrument are based on data from approximately 50,000 courses at 250 schools nationwide.

${ }^{8}$ This test has not counted toward the final graduate and has been given immediately following a major group project so that it is likely that the scores have reflected student knowledge prior to their review of course material in preparation for the final exam.

${ }^{9}$ Attendance was noncompulsory and records of the number of absences (but not which members) were kept by the groups.

${ }^{10}$ These include Accounting, Business Policy, Chemistry, Communications, Engineering, Geography, Statistics, and Zoology and in classes of up to 175 students.

${ }^{11}$ For example in Physical Chem istry each group should contain both chemistry and engineering majors. In organizational behavior an effort is made to insure that each group contains at least one member with work and/or military experience, another with a strong background in psychology and others from a mix of academic disciplines.

${ }^{32}$ Most students learn basic terminology and conceptual material when less than 25 percent of class time is devoted to individual and group exams covering assigned homework and subsequent instructor input. This is possible because very little class time is spent on concepts that students are able to grasp on their own.

${ }^{13} \mathrm{~A}$ number of studies have found that groups are superior to individuals solving problems that require either (1) the pooling of information or (2) applying concepts that have already been mastered in the abstract (Goldman, 1965; Laughlin \& Johnson, 1966).

${ }^{14} \mathrm{Group}$ membership can, however, "motivate students to go off and acquire new information on their own in order to overcome limitations in their knowledge which they discover through peergroup processes" (Bruffe, 1978, p. 454).

${ }^{15} \mathrm{~A}$ wide variety of strategies may be employed to reduce the probability that this situation will develop. Two of the most common are grading on a "curve" (Michaelsen, et al., 1981) and limiting the weight of contribution of group performance to the total grade.

${ }^{16}$ Secretaries generally can locate these. 
${ }^{17}$ Although we have no way to measure the impact of this emphasis on responsibility to the group for individual preparation and attendance several factors suggest that the method is very effective. For example, course evaluations indicate that either responsibility for or expectations of the group is more important than grades as a determinant of whether or not students complete their reading assignments. Also unknown absences seldom exceed one percent of total absences and generally are unavoidable (e.g., car trouble, accidents, sudden and severe illness).

${ }^{18} \mathrm{We}$ accept appeals from groups only, but the appeals count for the individual exams as well.
${ }^{19} \mathrm{We}$ either reproduce the best answer from the class or produce a composite.

${ }^{20}$ In a large class there are always at least one or two instances in which the same technical solution has a dramatically different effect on driver satisfaction. As a result, the discussion almost automatically focuses on what the leaders did that made the difference.

\title{
New Teaching Processes Series
}

Stimulated, in part, by Art Turner's article on case studies and the special section in Volume VI(4) on "Reflections on the Case Method," the Journal will run a regular series in each issue of EXCHANGE dedicated to a particular teaching process or method. Each topic area will have a subeditor who will coordinate that topic activity. This description is a call for interested sub-editors of such topic areas.

Some possible future topics are: "How to use personal diaries"; "Teaching through field projects"; "Experience with simulations"; "How to team teach"; "Effective use of teaching assistants"; "Experiences with skill development programs." Interested sub-editors of topic areas can select from this list or may propose their own topics. For now, the series will be confined to teaching methods or processes, as opposed to the content of courses or seminars.

The sub-editor's task will be to find contributors who will explore that topic from different viewpoints and orientations. He or she should also attempt to coordinate a dialogue amongst contributors and to encourage a high level of quality in the teaching advice given.

If you are interested in such a role, write to me and describe your topic area, your preliminary thoughts about how you would address the topic, from who you think you might solicit input, and how much lead time you think you'd like until your topic would appear in EXCHANGE.

\author{
Harvey Kolodny \\ Teaching Processes Editor \\ Faculty of Management Studies \\ University of Toronto \\ 246 Bloor Street West \\ Toronto, Ontario M5S 1V4, Canada
}

